\title{
Investigation of Dysregulation of Several MicroRNAs in Peripheral Blood of Schizophrenia Patients
}

\author{
Mehmet Akif Camkurt ${ }^{1}$, Fatih Karababa ${ }^{2}$, Mehmet Emin Erdal $^{3}$, Hüseyin Bayazıt ${ }^{4}$, Sultan Basmacı Kandemir ${ }^{5}$, \\ Mustafa Ertan $\mathrm{Ay}^{3}$, Hasan Kandemir ${ }^{6}$, Özlem İzci $\mathrm{Ay}^{3}$, Erdinç Çiçek ${ }^{7}$, Salih Selek ${ }^{8}$, Bahar Taşdelen ${ }^{9}$ \\ ${ }^{1}$ Psychiatry Clinic, Afşın State Hospital, Kahramanmaras, ${ }^{2}$ Psychiatry Clinic, Harran University Teaching Hospital, Şanliurfa, ${ }^{3}$ Department \\ of Medical Biology, Faculty of Medicine, Mersin University, Mersin, ${ }^{4}$ Psychiatry Clinic, Siverek State Hospital, Şanliurfa, ${ }^{5}$ Psychiatry Clinic, \\ Balıklıgöl State Hospital, Şanlıurfa, ${ }^{6}$ Department of Child and Adolescent Psychiatry, Harran University Teaching Hospital, Şanlıurfa, \\ ${ }^{7}$ Psychiatry Clinic, Çumra State Hospital, Konya, Turkey, ${ }^{8}$ Department of Psychiatry and Behavioral Sciences, Harris County Psychiatric \\ Center, University of Texas, Houston, TX, USA, ${ }^{9}$ Department of Biostatistics, Mersin University, Mersin, Turkey
}

Objective: The prevalence of schizophrenia is $1 \%$, and it is a debilitating disorder that often results in a shortened lifespan. Peripheral blood samples are good candidates to investigate because they can be easily drawn, and they are widely studied in psychiatric disorders. MicroRNAs are small non-coding RNA transcripts. They regulate the expression of genes by binding to the 3'-untranslated region (UTR) of mRNAs and pointing them to degrade. In this study, we aimed to investigate the expression of miR-9-5p, miR-29a-3p, miR-106-5p, miR-106b-5p, miR-107, miR-125a-3p, and miR-125b-3p in schizophrenia patients and healthy controls.

Methods: We collected blood samples from 16 patients with schizophrenia and 16 healthy controls. MicroRNAs were measured with reverse transcriptase polymerase chain reaction.

Results: Schizophrenia patients showed statistically significant upregulation of five microRNAs: miR9-5p ( $p=0.002)$, miR29a-3p $(p<0.001)$, miR106b-5p ( $p=0.002)$, miR125a-3p ( $p<0.001)$, and miR125b-3p ( $p=0.018)$.

Conclusion: Our results increased the value of the miR106 and miR29 families as potentially and consistently dysregulated in psychiatric disorders. Our results should be considered preliminary, and they need confirmation in future studies with larger sample sizes,

KEY WORDS: Blood; MicroRNAs; Schizophrenia; Genes.

\section{INTRODUCTION}

The prevalence of schizophrenia is $1 \%$, and it is a debilitating disorder that often results in a shortened lifespan. Many studies, including neuroimaging, genetic, or biochemical parameters, have been performed in an attempt to identify the neurobiology of schizophrenia. ${ }^{1-3)}$ Because of the mentioned burden of schizophrenia in patients' lives, researchers focused on identifying markers that represent disease status and prognosis. Peripheral tissues like plasma, serum, and lymphocytes are easily accessible, and are thus convenient to investigate. ${ }^{4)}$ In this context, many studies have been done to find peripheral markers like se-

\footnotetext{
Received: November 24, 2015 / Revised: December 26, 2015

Accepted: January 5, 2016

Address for correspondence: Mehmet Akif Camkurt, MD

Afşın State Hospital, Yeşilyurt mh., Kemal Ertekin Cd.,

Afşin/Kahramanmaraş 46500, Turkey

Tel: +90-344-511-53-05, Fax: +90-344-511-29-66

E-mail:dr.akif@gmail.com
}

rum interleukins, leptin, oxidative stress parameters, and antioxidant enzyme activity for psychiatric disorders. ${ }^{5-9}$ )

MicroRNAs are approximately 22-nucleotide-long, small non-coding RNA transcripts. They bind to the 3'-untranslated region of mRNAs and induce degradation of pointed mRNA. The interaction between microRNAs and mRNAs usually results in decreased gene expression in a cell. ${ }^{10,11)}$ Although microRNAs usually decrease the translation of mRNA, they rarely increase translation. ${ }^{12)}$ With this mechanism, microRNAs have the potential to regulate more than 10,000 genes in the cell. ${ }^{13)}$ Previous studies have shown the importance of microRNAs for several psychiatric disorders. Perkins et al. ${ }^{14)}$ found that miR-9 and miR-29 were downregulated and miR-106 was upregulated in the prefrontal cortex of schizophrenia patients. MicroRNA analysis of the dorsolateral prefrontal cortex and superior temporal gyrus in schizophrenia patients revealed upregulation of miR-107 and

(a) This is an Open-Access article distributed under the terms of the Creative Commons Attribution Non-Commercial License (http://creativecommons.org/licenses/by-nc/4.0) which permits unrestricted non-commercial use, distribution, and reproduction in any medium, provided the original work is properly cited. 
Table 1. Importance of selected microRNAs depending on previous literature

\begin{tabular}{|c|c|c|c|c|}
\hline microRNA & Psychiatric disease & Tissue & Result & Reference \\
\hline miR-106 & Depression & Plasma & Upregulated & Liu et $a l^{16)}$ \\
\hline miR-106b-5p & $\begin{array}{l}\text { Attention deficit and } \\
\text { hyperactivity disorder }\end{array}$ & Plasma & Downregulated & Kandemir et $a l^{17)}$ \\
\hline $\begin{array}{l}\text { miR-9-3p } \\
\text { miR-29a }\end{array}$ & Schizophrenia & Prefrontal cortex & Downregulated & Perkins et $a l^{14)}$ \\
\hline mir-106b & & & Upregulated & \\
\hline miR-107 & Alzheimer disease & Cortical tissue & Downregulated & Wang et $a l^{18)}$ \\
\hline miR-107 and miR-125 & Schizophrenia & $\begin{array}{l}\text { Prefrontal cortex, superior } \\
\text { temporal gyrus }\end{array}$ & Upregulated & Beveridge et $a l^{15)}$ \\
\hline miR-125b & & Mice brain & Related with FMRP & Edbauer et al. $^{19)}$ \\
\hline
\end{tabular}

FMRP, fragile $X$ mental retardation protein.

miR-125. ${ }^{15)}$ Furthermore, miR-106 was reported to be upregulated in the plasma of patients with depression and downregulated in the plasma of attention deficit and hyperactivity disorder (ADHD) patients. ${ }^{16,17)}$ In Table $1,{ }^{14-19)}$ several miRNAs that we studied and their relevance with psychiatric disorders are shown.

Depending on increasing data about the importance of microRNAs in psychiatric disorders, we aimed to investigate different expression profiles of miR-9-5p, miR29a-3p, miR-106a-5p, miR-106b-5p, miR-107, miR$125 a-3 p$, and miR-125b-3p in the plasma of schizophrenia patients and healthy controls.

\section{METHODS}

\section{Participants}

Sixteen patients diagnosed with schizophrenia according to the the Diagnostic and Statistical Manual of Mental Disorders 4th edition, text revision (DSM-IV-TR) criteria and admitted to the Psychiatry Clinic of Harran University Medical Faculty Hospital were included in our study. An adult psychiatrist validated the diagnoses of the patients. We excluded patients with comorbid psychiatric or medical illnesses. Sixteen healthy volunteers were included in the control group of our research. Written and verbal informed consent was obtained from patients and healthy volunteers. All of the procedures of the study were executed according to the principles of the Helsinki Declaration, and the Harran University Ethical Committee approved it (date:10.01.2012, no:76).

\section{RNA Extraction}

Total RNA was extracted from Peripheral whole blood using Tri-Reagent (Sigma, Taufkirchen, Germany).

\section{Reverse Transcriptase Polymerase Chain Reactions (RT-PCR)}

RT-PCR contained $5 \mu$ l of extracted total RNA, $50 \mathrm{nM}$ stem-loop RT primer, $1 \times$ RT buffer, $0.25 \mathrm{mM}$ each of dNTPs, 50 units of modified M-MuLV Reverse Transcriptase (Thermo Scientific, Vilnius, Lithuania), 25 units of RiboLock RNase inhibitor (Thermo Scientific) and nuclease-free water to a total reaction volume of $15 \mu \mathrm{l}$. The reaction was performed on an automated Thermal Cycler (Veriti, Applied Biosystems, Foster City, CA, USA). RT-PCR conditions for 30 minutes at $16^{\circ} \mathrm{C}, 30$ minutes at $42^{\circ} \mathrm{C}, 5$ minutes at $85^{\circ} \mathrm{C}$ and then held at $4^{\circ} \mathrm{C}$.

\section{Quantitative-Comparative CT ( $\Delta \Delta \mathrm{CT}$ ) Real-time PCR}

$\triangle \triangle \mathrm{CT}$ Real-time PCR was performed in an $\mathrm{ABI}$ Prism 7500 Real-Time PCR System using the SDS 2.0.6 software (Applied Biosystems). The specific primers and fluorogenic $\mathrm{ZNA}^{\mathrm{TM}}$ probes for the microRNAs were designed using Primer Express 3.0 software (Applied Biosystems) and defined in the article of Kandemir et al. ${ }^{17)}$ The hsa-miR-26b-5p was used as an endogenous control microRNA. The mixed RNAs generated from the control group was used as a Reference RNA sample. Primers and probes were purchased from Metabion International (Martinsried, Germany). The $25 \mu \mathrm{l} \mathrm{PCR}$ included $3 \mu \mathrm{l}$ RT-PCR product, $12.5 \mu \mathrm{l}$ of $2 \mathrm{X}$ TaqMan Universal PCR Master Mix (Applied Biosystems), $900 \mathrm{nmol}$ of each primer (Primer F and Universal Primer R) and $200 \mathrm{nmol}$ TaqMan probe. The reactions were incubated in a 96 -well plate of preincubation at $50^{\circ} \mathrm{C}$ for 2 minutes and at $95^{\circ} \mathrm{C}$ for 10 minutes, followed by 40 cycles at $95^{\circ} \mathrm{C}$ for $15 \mathrm{sec}-$ onds and at $60^{\circ} \mathrm{C}$ for 90 seconds. All reactions were run in triplicate.

\section{Statistical Analysis}

The data were processed and analyzed using the SPSS software package for Windows (version 16.0; SPSS Inc., 
Chicago, IL, USA). Normality assumption of $2^{-\Delta \Delta \mathrm{CT}}$ values was checked by Shapiro-Wilk test. Since the assumption of normality was not met, the comparisons between groups were performed using Mann-Whitney $U$-test. Descriptive statistics for $2^{-\Delta \Delta \mathrm{CT}}$ values were expressed as mean, standard deviation, median, first quartile (25th percentile) and third quartile (75th percentile). Significant differences (two-tailed $p$ ) less than 0.05 were regarded as significant. Parametric variables (age) compared with Student $t$-test. Chi-square test used to compare gender between groups.

\section{RESULTS}

We found no significant difference between the groups regarding gender and age, as shown in Table 2.

All of the patients were in active psychotic episode. The clinical characteristics of the patients were as follows: Three patients were drug-naïve and first episode, and 13 patients were previously on atypical antipsychotic treatment. The average duration of illness was $7.5 \pm 1.7$ years. Routine biochemical examinations of patients were within the normal range.

We compared the microRNA expression levels of the schizophrenia group with controls. Compared with the controls, as shown in Table 3, schizophrenia patients showed statistically significant upregulation of five microRNAs: miR9-5p ( $p=0.002), \operatorname{miR} 29 \mathrm{a}-3 \mathrm{p}(p<0.001)$, miR106b-5p $(p=0.002), \operatorname{miR} 125 \mathrm{a}-3 \mathrm{p} \quad(p<0.001)$, and $\operatorname{miR} 125 \mathrm{~b}-3 \mathrm{p}(p=0.018)$.

Table 2. Sociodemographic traits of the groups

\begin{tabular}{lccc}
\hline & $\begin{array}{c}\text { Schizophrenia } \\
(n=16)\end{array}$ & $\begin{array}{c}\text { Controls } \\
(n=16)\end{array}$ & $p$ value \\
\hline Age $(\mathrm{yr})$ & $34.6 \pm 9.2$ & $32.5 \pm 8.4$ & 0.501 \\
Gender $(\mathrm{F} / \mathrm{M})$ & $8 / 8$ & $8 / 8$ & 1.0
\end{tabular}

Values are presented as mean \pm standard deivation or number only.

F, female: $M$, male

Two groups are similar in terms of age and gender. We found no significant difference among them.

\section{DISCUSSION}

The main findings of our study are the upregulation of five microRNAs (miR9-5p, miR-29a-3p, miR106b-5p, miR125a-3p, and miR125b-3p) in schizophrenia patients. As previously noted, several dysregulated microRNAs in the plasma of schizophrenia patients were miR-181b, miR219-2-3p, miR346, miR195, miR1308, miR92a, miR17, mirR103, let-7g, miR181b, mir30e, mir34a, and mir $7 .^{20,21)}$ Our study adds five potential new microRNAs to this field. After searching databases, we found that these five microRNAs are related to several important genes for schizophrenia (Table 4). ${ }^{22)}$ miR-9 is related to the glycogen synthase kinase $3 \mathrm{~B}$ interactin protein (GSKIP), which modulates GSK3B signaling, and important for schizophrenia. ${ }^{23)} \mathrm{miR}-29$ targets the glutamate receptor 3 (GRIA3) gene, which is also associated with schizophrenia. ${ }^{24)}$ HTR2A and SLC17A7 (known as the vesicular glutamate transporter 1 [VGLUT1]) are targets for miR-106b, and HTR2A is involved in epigenetic disturbances in schizophrenia. ${ }^{25)}$ miR125a targets the GRIP2 gene, which is altered in the superior temporal cortex of

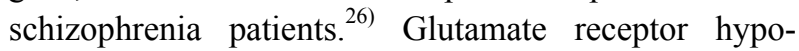

Table 3. Comparison of microRNA levels between schizophrenia patients and healthy controls

\begin{tabular}{lccc}
\hline $\begin{array}{c}\text { MicroRNA } \\
\text { level }\end{array}$ & $\begin{array}{c}\text { Control } \\
(\mathrm{n}=16)\end{array}$ & $\begin{array}{c}\text { Schizophrenia } \\
(\mathrm{n}=16)\end{array}$ & $p$ value* \\
\hline miR9-5p & 0.54 & 4.10 & $0.002^{*}$ \\
miR29a-3p & $0.37-0.95)$ & $(2.41-5.38)$ & \\
& 0.0009 & 0.0326 & $<0.001^{*}$ \\
miR106a-5p & $(0.0005-0.0039)$ & $(0.0219-0.0514)$ & \\
& $(0.5469-3.9152)$ & $(2.7856-6.7942)$ & 0.089 \\
miR106b-5p & 0.9353 & 8.3803 & $0.002^{*}$ \\
miR107 & $(0.5019-1.6489)$ & $(3.6318-32.6446)$ & \\
& 6.3747 & 6.5119 & 0.724 \\
miR125a-3p & $(0.8042-8.0077)$ & $(4.6031-17.3886)$ & \\
& 0.5108 & 24.3688 & $<0.001^{*}$ \\
miR125b-3p & $0.2495-1.6409)$ & $(14.0268-30.0851)$ & \\
& 0.1454 & 0.5433 & $0.018^{*}$ \\
& $(0.0844-0.3232)$ & $(0.2974-1.4554)$ & \\
\hline
\end{tabular}

Values are presented as median (interquartile range).

*Statistically up regulated in schizophrenia patients compared to the healthy controls.

Table 4. Predicted target genes and pathways for selected microRNAs*

\begin{tabular}{|c|c|c|c|c|}
\hline & Target gene $(s)^{22) * *}$ & Pathway & Disorder & Reference \\
\hline miR-9 & GSKIP & GSK3 & Schizophrenia & Emamian ${ }^{23)}$ \\
\hline miR-29 & GRIA3 & Glutamate & Schizophrenia & Magri et $a l^{24)}$ \\
\hline miR-106b & HTR2A，SLC17A7 & $5 \mathrm{HT}_{2}$ receptor, Glutamate & Schizophrenia & Abdolmaleky et $a l^{25)}$ \\
\hline miR-125a & GRIP2 & Glutamate & Schizophrenia & Bowden et $a l^{26)}$ \\
\hline
\end{tabular}

*Significantly upregulated in this study. 
function and decreased levels of glutamate have been reported in schizophrenia. ${ }^{27-29)}$ Upregulation of microRNAs usually results in decreased gene expression. In this regard, increased microRNA levels that target glutamatergic pathways may result in decreased glutamatergic transmission. We think that the examination of possible interactions between microRNAs and glutamatergic pathways could be helpful for further understanding of schizophrenia.

We found miR-106b-5p to be upregulated in schizophrenia patients. In their study, Liu et al. ${ }^{16)}$ compared 14 healthy controls with 16 depressed patients and found that miR106-5p and four other microRNAs were upregulated in the plasma of depressed patients. Additionally, miR106b-5p was found to be downregulated in children with ADHD. ${ }^{17)}$ We believe that combining our results with previous findings increases the likelihood that the miR-106 family is a potential plasma marker for psychiatric disorders.

Several studies investigated miR-9, miR-29, miR-106, and miR-125 in schizophrenia. Evaluating these studies together reveals that the same microRNA may be expressed differentially in diverse brain regions. For instance, Perkins et al. ${ }^{14)}$ found that miR-9 was downregulated in the prefrontal cortex of individuals with schizophrenia, while Beveridge et al ${ }^{15)}$ found miR-9 to be upregulated in the superior temporal gyrus. Anther point is that the same microRNAs may be expressed diversely between brain tissue and peripheral tissues. Although a study noted that miR-107 was upregulated in the dorsolateral prefrontal cortex, Gardiner et al. ${ }^{30)}$ found that miR-107 was downregulated in peripheral blood mononuclear cells.

The limitations of our study are its small sample size, its cross-sectional design, and the limited number of microRNA types analyzed.

In brief, we found five microRNAs that were upregulated in schizophrenia patients. These microRNAs are predicted to be targeting important genes for schizophrenia. Evaluating our results with previous data increases the importance of the miR-106 family as a potential plasma marker for psychiatric disorders. While investigating microRNA in psychiatric disorders, authors should keep in mind that microRNAs are affected by age, diet, exercise, and acute or chronic diseases. Strict exclusion criteria should be determined to provide a homogeneous study population. Although we found upregulation of five microRNAs in the plasma of schizophrenia patients, these findings should be considered preliminary and specific to plasma, because microRNA expressions may alter in different tissues, and even in different regions of the same tissue.

\section{Acknowledgments}

We thank to Harran University HÜBAK Commission for funding of our research project (funding number: 12004).

\section{REFERENCES}

1. Vijayakumari AA, John JP, Halahalli HN, Paul P, Thirunavukkarasu $\mathrm{P}$, Purushottam M, et al. Effect of polymorphisms of three genes mediating monoamine signalling on brain morphometry in schizophrenia and healthy subjects. Clin Psychopharmacol Neurosci 2015;13:68-82.

2. Kuswanto CN, Teh I, Lee TS, Sim K. Diffusion tensor imaging findings of white matter changes in first episode schizophrenia: a systematic review. Clin Psychopharmacol Neurosci 2012;10:13-24.

3. Smyth AM, Lawrie SM. The neuroimmunology of schizophrenia. Clin Psychopharmacol Neurosci 2013;11:107-117.

4. Biomarkers Definitions Working Group. Biomarkers and surrogate endpoints: preferred definitions and conceptual framework. Clin Pharmacol Ther 2001;69:89-95.

5. Camkurt MA, Acar Ş, Coşkun S, Güneş M, Güneş S, Y1lmaz MF, et al. Comparison of plasma MicroRNA levels in drug naive, first episode depressed patients and healthy controls. J Psychiatr Res 2015;69:67-71.

6. Al-Amin MM, Nasir Uddin MM, Mahmud Reza H. Effects of antipsychotics on the inflammatory response system of patients with schizophrenia in peripheral blood mononuclear cell cultures. Clin Psychopharmacol Neurosci 2013; 11:144-151.

7. Park MH, Kwon YJ, Jeong HY, Lee HY, Hwangbo Y, Yoon $\mathrm{HJ}$, et al. Association between Intracellular Infectious Agents and Schizophrenia. Clin Psychopharmacol Neurosci 2012; 10:117-123.

8. Neelamekam S, Nurjono M, Lee J. Regulation of interleukin-6 and leptin in schizophrenia patients: a preliminary analysis. Clin Psychopharmacol Neurosci 2014;12:209-214.

9. Herken H, Uz E, Ozyurt H, Sögüt S, Virit O, Akyol O. Evidence that the activities of erythrocyte free radical scavenging enzymes and the products of lipid peroxidation are increased in different forms of schizophrenia. Mol Psychiatry 2001;6:66-73.

10. Filipowicz W, Bhattacharyya SN, Sonenberg N. Mechanisms of post-transcriptional regulation by microRNAs: are the answers in sight? Nat Rev Genet 2008;9:102-114.

11. Novina CD, Sharp PA. The RNAi revolution. Nature 2004; 430:161-164.

12. Place RF, Li LC, Pookot D, Noonan EJ, Dahiya R. MicroRNA-373 induces expression of genes with complementary promoter sequences. Proc Natl Acad Sci U S A 2008; 105:1608-1613.

13. Zhang J, Liu Q, Zhang W, Li J, Li Z, Tang Z, et al. Comparative profiling of genes and miRNAs expressed in the newborn, young adult, and aged human epididymides. Acta Biochim Biophys Sin (Shanghai) 2010;42:145-153.

14. Perkins DO, Jeffries CD, Jarskog LF, Thomson JM, Woods $\mathrm{K}$, Newman MA, et al. microRNA expression in the prefrontal cortex of individuals with schizophrenia and schizoaffective disorder. Genome Biol 2007;8:R27. 
15. Beveridge NJ, Gardiner E, Carroll AP, Tooney PA, Cairns MJ. Schizophrenia is associated with an increase in cortical microRNA biogenesis. Mol Psychiatry 2010;15:1176-1189.

16. Liu X, Zhang L, Cheng K, Wang X, Ren G, Xie P. Identification of suitable plasma-based reference genes for miRNAome analysis of major depressive disorder. J Affect Disord 2014;163:133-139.

17. Kandemir H, Erdal ME, Selek S, Ay Öİ, Karababa IF, Kandemir SB, et al. Evaluation of several micro RNA (miRNA) levels in children and adolescents with attention deficit hyperactivity disorder. Neurosci Lett 2014;580: 158-162.

18. Wang WX, Rajeev BW, Stromberg AJ, Ren N, Tang G, Huang Q, et al. The expression of microRNA miR-107 decreases early in Alzheimer's disease and may accelerate disease progression through regulation of beta-site amyloid precursor protein-cleaving enzyme 1. J Neurosci 2008;28: 1213-1223.

19. Edbauer D, Neilson JR, Foster KA, Wang CF, Seeburg DP, Batterton MN, et al. Regulation of synaptic structure and function by FMRP-associated microRNAs miR-125b and miR-132. Neuron 2010;65:373-384.

20. Shi W, Du J, Qi Y, Liang G, Wang T, Li S, et al. Aberrant expression of serum miRNAs in schizophrenia. J Psychiatr Res 2012;46:198-204.

21. Song HT, Sun XY, Zhang L, Zhao L, Guo ZM, Fan HM, et al. A preliminary analysis of association between the down-regulation of microRNA-181b expression and symptomatology improvement in schizophrenia patients before and after antipsychotic treatment. J Psychiatr Res 2014;54:134140.
22. Wong N, Wang X. miRDB: an online resource for microRNA target prediction and functional annotations. Nucleic Acid Res 2015:43:D146-D152.

23. Emamian ES. AKT/GSK3 signaling pathway and schizophrenia. Front Mol Neurosci 2012;5:33.

24. Magri C, Gardella R, Valsecchi P, Barlati SD, Guizzetti L, Imperadori L, et al. Study on GRIA2, GRIA3 and GRIA4 genes highlights a positive association between schizophrenia and GRIA3 in female patients. Am J Med Genet B Neuropsychiatr Genet 2008;147B:745-753.

25. Abdolmaleky HM, Yaqubi S, Papageorgis P, Lambert AW, Ozturk S, Sivaraman V, et al. Epigenetic dysregulation of HTR2A in the brain of patients with schizophrenia and bipolar disorder. Schizophr Res 2011;129:183-190.

26. Bowden NA, Scott RJ, Tooney PA. Altered gene expression in the superior temporal gyrus in schizophrenia. BMC Genomics 2008;9:199.

27. Olney JW, Farber NB. Glutamate receptor dysfunction and schizophrenia. Arch Gen Psychiatry 1995;52:998-1007.

28. Kim JS, Kornhuber HH, Schmid-Burgk W, Holzmüller B. Low cerebrospinal fluid glutamate in schizophrenic patients and a new hypothesis on schizophrenia. Neurosci Lett 1980;20:379-382.

29. Eastwood SL, Harrison PJ. Decreased expression of vesicular glutamate transporter 1 and complexin II mRNAs in schizophrenia: further evidence for a synaptic pathology affecting glutamate neurons. Schizophr Res 2005;73:159-172.

30. Gardiner E, Beveridge NJ, Wu JQ, Carr V, Scott RJ, Tooney $\mathrm{PA}$, et al. Imprinted DLK1-DIO3 region of $14 q 32$ defines a schizophrenia-associated miRNA signature in peripheral blood mononuclear cells. Mol Psychiatry 2012;17:827-840. 